\title{
Doğal Yeşil Lif Rengine Sahip Pamukta (Gossypium spp.) Resiprokal F6 ve F9 Melez Kuşaklarının Karşılaştırılması
}

\author{
Ramazan Şadet GÜVERCIN ${ }^{1}$ \\ ${ }^{1}$ Kahramanmaraş Sütçü İmam Üniversitesi, Türkoğlu Meslek Yüksek Okulu, Türkoğlu/Kahramanmaraş \\ $\bowtie$ : rguvercin@hotmail.com
}

Geliş (Received): 03.11.2017

Kabul (Accepted): 15.12.2017

\begin{abstract}
ÖZET: Beyaz rengin dışında, farklı ve doğal lif rengine sahip pamuklara, renkli pamuk denilmektedir. Bu araştırmada, doğal yeşil lif rengine sahip olmakla birlikte, lif kalite özellikleri zayıf bir pamuk (Gossypium hirsutum L.) genotipi ile kalite özellikleri yüksek Giza 45 (Gossypium barbadense L.) çeşidinin resiprokal F6 ve F9 melez kuşakları incelenmiştir. Çalışma, 2006 (F6) ve 2010 (F9) yıllarında, Doğu Akdeniz Geçit Kuşağı Tarımsal Araştırma Enstitüsü Müdürlüğ̈̈’nde, sıra uzunluğu $12 \mathrm{~m}$, sira arası $0.70 \mathrm{~m}$ ve sıra üzeri mesafe ise $0.15 \mathrm{~m}$ olarak düzenlenmiş parsellerde, Augmented Deneme Deseni'ne göre yürütülmüştür. Çalışmada, ortalamalar üzerinden kütlü pamuk verimi, çıç̧ır randımanı, lif verimi, lif inceliği, lif uzunluğu, lif mukavemeti ve lif üniformitesi yönünden resiprokal F6 ve F9 kuşakları karşılaştırılmışıtır.

Araştırma sonucunda ise resiprokal melezlerin kütlü pamuk verimi ve çırçır randımanının yanı sıra life ait verim, incelik ve mukavemet yönünden olumlu yönde benzerlik gösterirken, lif üniformitesi ve lif uzunluğu yönünden ayrıştığı tespit edilmiş̧ir.

Anahtar kelimeler; Kahramanmaraş, renkli pamuk, resiprokal F6 ve F9 generasyonları
\end{abstract}

\section{Comparison of Reciprocal Hybrids of Cotton (Gossypium spp.) Having Naturally Green Fiber at F6 and F9 Generations}

\begin{abstract}
A cotton, having naturally colored fibers instead of white, is called as colored cotton. In this study, reciprocal F6 and F9 hybrid generations with a natural green-colored fiber were examined. They are offspring of Gossypium barbadense L. (Giza 45) and Gossypium hirsutum L. Giza 45 variety having high fiber quality values was crossed with a cotton genotype from Gossypium hirsutum L. having green color and poor fiber. The study was carried out in 2006 (F6) and 2010 (F9) years at the East Mediterranean Transitional Zone Agricultural Research of Institute in Augmented Design. All plots were arranged $12 \mathrm{~m}$ length with $0.70 \mathrm{~m}$ space between two rows, and 0.15 $\mathrm{m}$ space between plants in same row. In the study, the values of seed cotton yield, gin turn out, fiber yield, fineness, length, strength and uniformity were examined and the reciprocal F6 and F9 generations were compared on the averages of these properties. As a result of research, it was determined that reciprocal hybrids have similarity with respect to seed cotton yield, gin turnout, fiber yield, fiber fineness and fiber strength, except uniformity ratio and fiber length.

Key Words: Kahramanmaraş, colored cotton, reciprocal F6 and F9 generations
\end{abstract}

\section{GİRIŞ}

Beyaz rengin dışında, farklı ve doğal lif rengine sahip pamuklara renkli pamuk denilmektedir. Lif rengi, genetiksel özellik olmakla birlikte, bu liflere sahip genotipler, yeterli olmayan verim ve kalite değerleri ile tekstil sektörünün taleplerini karşılamamaktadır (Backe, 1994). Bu durumu ilk defa fark eden Sally Fox, başlattığ 1 slah programı neticesinde makine ile eğrilebilen lif uzunluğuna sahip, yeni hibritler geliştirmiş ve bu olumsuzlukları kısmen gidermiş̧ir (Fox, 1987). Renkli pamuklardan yapılan ipler ve kumaşlar, boyanmaya ihtiyaç duymazlar. Bu sayede, tüketiciler kimyasal boya etkilerine bağlı alerjik sorunlardan, tekstil üreticileri ise yüksek boya maliyetlerinden kurtulmaktadırlar (Apodaca, 1990). Ancak, ticari anlamda renkli pamuklardan bu faydanın sağlanabilmesi, yeterli verim, çırçır randımanı ve lif özelliklerinin kombine edilmesine bağlıdır.

Günümüzde, beyaz rengin dişında doğal üç ana (yeşil, taba ve kahverengi) renk ile bu renklerin farklı tonlarına sahip genotipler bulunmaktadır. Kahverenkli pamuklarda verim ve lif kalitesi yönünde yakalanan kısmi başarı, bu genotiplerin üretimini ve ticaretini kolaylaştırırken, yeşil lifli genotip/lerde ticarete konu olabilcek başarı hala yakalanamamıştır. Oysa, yabani pamuk türleri lif rengi yönünden önemli gen kaynaklarıdır. Pamuk yetiştiren diğer ülkelerde olduğu gibi, ülkemizde de renkli life sahip pamuklar geliştirmek amacıyla bu gen kaynaklarının kullanıldığı çok sayıda islah çalışmaları yürütülmüştür. Islah çalışmaları; tür içi (Kaynak, 1999) ve türler arası (Güvercin ve ark., 2007) olmakla birlikte, çalışmalarda daha çok verim, hibrit gücü ve renk kalıtımı incelenmiștir. Kaynak (1999), Gossypium hirsutum L. türüne ait Nazilli 84 çeşidinin, aynı türe ait yeşil lifli genotiplerinden kütlü pamuk verimi, erkencilik oranı, odun dalı sayısı, çırçır randımanı ile life ait uzunluk, mukavemet, incelik ve yeknesaklık yönünden pozitif ayrıştığını bildirmiştir. Araştırıcı, $F_{1}$ populasyonunda erkencilik oranı, yüz tohum ağırlığı, kütlü pamuk verimi ve lif mukavemeti yönünden önemli hibrit gücü olduğunu bildirirken, $\mathrm{F}_{2}$ populasyonunda yeşil lif rengi 
yönünden 37 farklı renk yoğunluğunun bulunduğu ve lif renginin tek gen çifti ile yönetildiğini, $F_{3}$ populasyonunda ise lif rengi ile incelenen özellikler arasında var olan olumsuz ilişkinin kırılamadığını bildirmiştir. Diğer yönden, türler arası (Gossypium hirsutum L. x Gossypium barbadense L.) çalışan Güvercin ve ark. (2007) ise $F_{1}$ melezlerinde life ait uzunluk, incelik, mukavemet ve üniformite yönünden olumlu ve önemli hibrit gücü olduğunu bildirmenin yanı sıra hibrit gücünün sonraki kuşaklara aktarılamadığını ve incelenen özelliklere ait değerlerin, daha çok renkli life sahip ebeveyne yaklaştığını saptamıştır. Diğer bazı araştırıcılar da yeşil lif renginin tek gen çifti tarafindan kontrol edildiğini (Richmond,1943; Fan ve ark. 2009; Wu ve ark. 2010) bildirirken, Cuming ve ark. (2015) dominant tek gen tarafindan kontrol edildiğini bildirmiştir.

$\mathrm{Bu}$ çalışma, yeşil lif rengine sahip olmakla birlikte, lif özellikleri zaylf bir pamuk (Gossypium hirsutum L.) genotipi ile lif özellikleri üstün Giza 45 (Gossypium barbadense L.) çeşidine ait resiprokal melezlerin $\mathrm{F}_{6}$ (2006) ile $F_{9}$ (2010) generasyonlarını, kütlü pamuk verimi, çırçır randımanı ile life ait verim incelikği, uzunluk, mukavemet ve üniformitesi yönünden karşılaştırarak uygun kombinasyonları saptamak amacıyla Kahramanmaraş koşullarında yürütülmüştür.

\section{MATERYAL ve METOT}

Çalışma, Doğu Akdeniz Geçit Kuşağı Tarımsal Araştırma Enstitüsü Müdürlüğü'nde, Augmented deneme desenine göre yürütülen ıslah programının, 2006 ve 2010 yıllarına ait bir bölümü kapsamaktadır. Çalışmada, doğal yeşil lifli pamuk (Gossypium hirsutum
L.) genotipi ile Giza 45 (Gossypium barbadense L.) çeşidinin resiprokal $\mathrm{F}_{6} \quad$ (2006) ve $\mathrm{F}_{9}$ (2010) generasyonları bitkisel materyal olarak kullanılmıştır. Genotiplere ait kütlü pamuk verimi, çırçır randımanı ve lif verimi; sira uzunluğu $12 \mathrm{~m}$, sira aras $0.70 \mathrm{~m}$ ve sira üzeri $0.15 \mathrm{~m}$ olarak düzenlenen parseller yardımıyla, life ait incelik, uzunluk, mukavemet ve üniformite ise HVI (Hight volume instirumens) 900 cihazı ile saptanmıştır. Resiprokal melezlerin karşılaştırılması ise tekerrür ortalamaları üzerinden açıklı, standart sapma ve "t" testi ile yapılmıştır.

\section{BULGULAR ve TARTIŞMA \\ Kütlï pamuk verimi $\left(\mathrm{kgda}^{-1}\right)$}

Renkli life sahip pamukların, beyaz lifli pamuklara oranla az verimli olduğu bilinmektedir (Efe ve ark., 2010). Bu çalışmada yer alan genotiplerin 2006 yılı verim ortalamas1 $206.89 \mathrm{kgda}^{-1}, 2010$ y1 verim ortalaması ise $249.67 \mathrm{kgda}^{-1}$ olarak saptanmıştır (Çizelge 1). En yüksek kütlü pamuk verimi 2006 yılında Giza 45 (235.45 $\left.\mathrm{kgda}^{-1}\right), 2010$ y1lında ise Yeşil x Giza $^{\circ}$ $45^{\text {3 }}\left(\mathrm{F}_{9}\right)$ melezinden elde edilirken, en düşük verim 2006 yılında yeşil lifli, 2010 yılında da Giza 45 ebeveynlerinden elde edilmiştir. $\mathrm{F}_{9}$ generasyonundaki resiprokal melezler, $\mathrm{F}_{6}$ generayonundan daha verimli bulunurken, resiproklar arasi fark her iki generayonda da önemsiz bulunmuştur. Yeşil lifli ebeveyne ait bulgular Kaynak (1999)'ın yanı sıra, Başbağ ve Temiz (2004) ile uyum gösterirken, ebeveynlerin resiprokal melezlerden, $F_{6}$ generasyonunun $F_{9}$ generasyonundan, Giza 45 \% $\times$ Yeşi $^{\hat{t}}$ kombinasyonunun ise resiprokal melezinden (Yeşil o x Giza 45 $5^{\text {) }}$ ) daha stabil olduğu, açıklık ve standart sapma değerlerinden anlaşılmaktadır.

Çizelge 1. Genotiplerin $\mathrm{F}_{6}$ ve $\mathrm{F}_{9}$ generasyonlarına ait kütlü pamuk verimleri

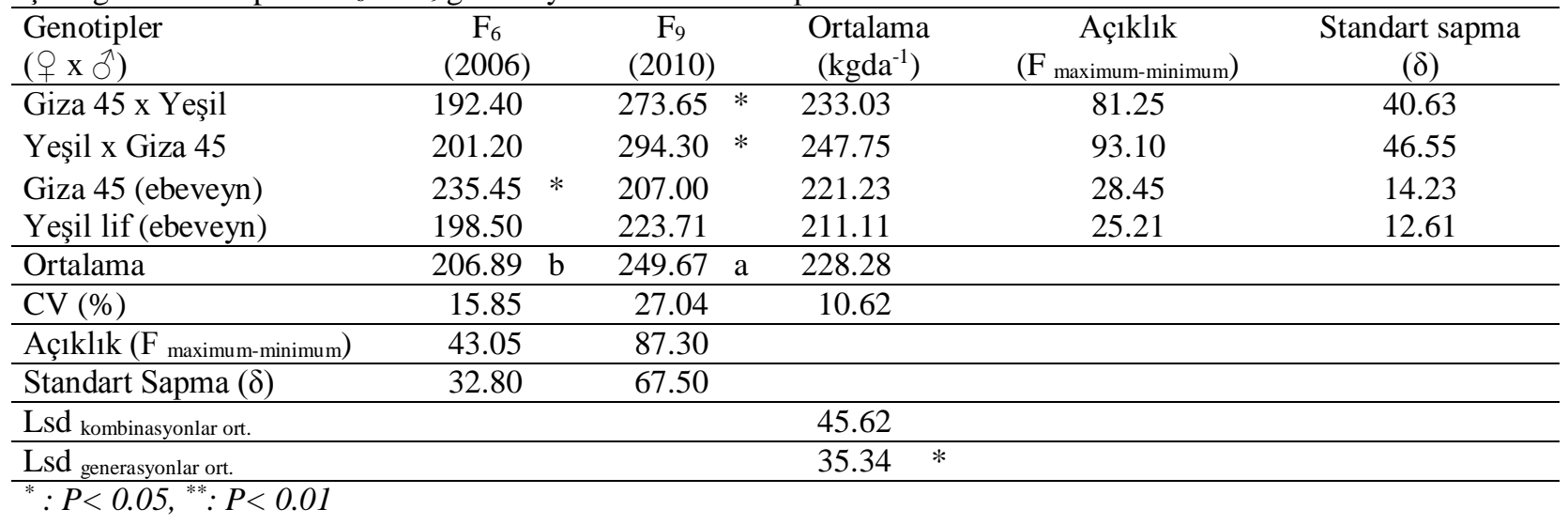

\section{Çırçır randımanı (\%)}

Genotiplere ait çırçır randımanları, ebeveynlere ait genetik potansiyelden dolayı oldukça düşük bulunmuştur (Çizelge 2). Çalışmada 2006 yılına ait çırçır randımanı ortalaması \% 29.57, 2010 yılına ait çırçır randımanı ortalaması ise \% 31.51 olarak gerçekleşirken, genotiplerin $\mathrm{F}_{9}$ generasyonundaki çırçır randımanları, Giza 45 hariç, $\mathrm{F}_{6}$ generasyonundan daha yüksek bulunmuştur. Bu durum, seleksiyon baskısı ve çevre koşullarıyla açıklanırken, resiprokal melezler her iki generasyonda da birbirine üstünlük sağlamamıştır. Başbağ ve Temiz (2004) yeşil lifli genotiplerinin \% 30.76, Efe ve ark. (2010) ise \% 34.1 oranında çırçır randımanına sahip olduğunu bildirirken, bu çalışmada yeşil lifli ebeveynin daha düşük, $F_{6}$ ve $F_{9}$ generasyonlarının ise daha yüksek çırçır randımanına sahip olduğu saptanmıştır. 
Çizelge 2. Genotiplerin $\mathrm{F}_{6}$ ve $\mathrm{F}_{9}$ generasyonlarına ait çırçır randımanları

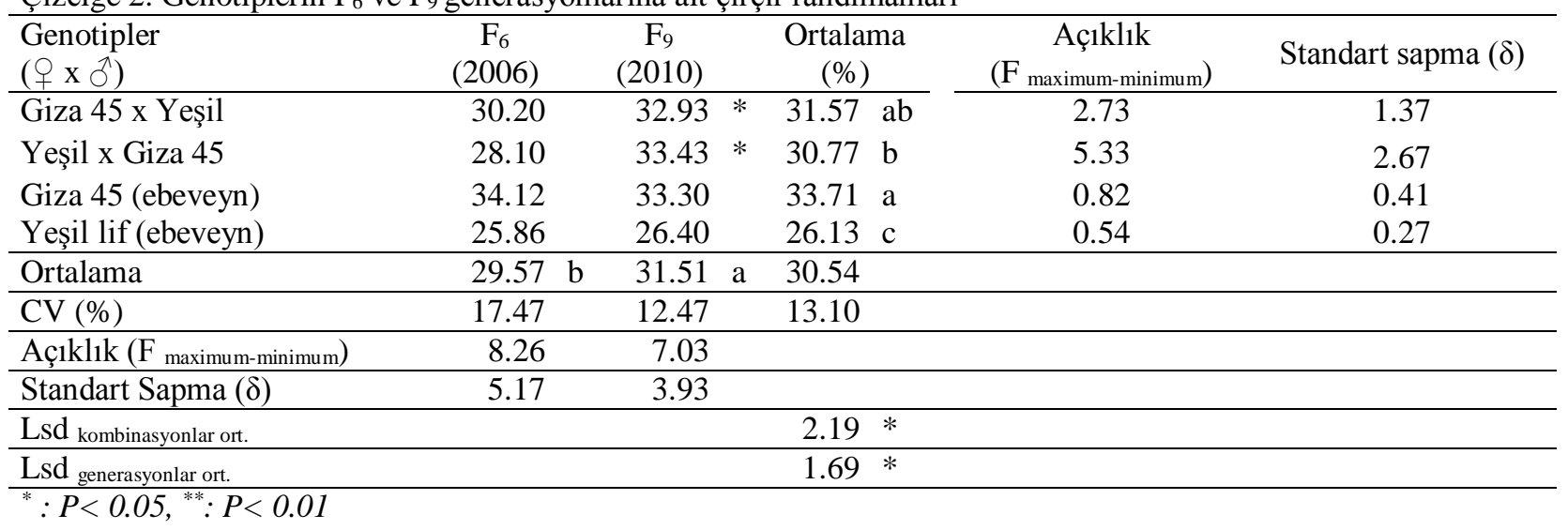

Giza 45 (\%34.12) çeşidi 2006 y1lında, Yeşil x Giza $45^{\text {to }}$ kombinasyonu $\left(\mathrm{F}_{9}\right)$ ise 2010 yllında en yüksek çırçır randımanına sahipken, yeşil lifli ebeveyn hem 2006 hem de 2010 yıllarında en düşük çırçır randımanına sahip olmuştur. Ebeveynlerin resiprokal melezlerden, $\mathrm{F}_{9}$ generasyonunun ise $\mathrm{F}_{6}$ generasyonundan daha stabil olduğu çalışmada, Giza 45 o x Yeşil ${ }^{8}$ kombinasyonu resiprokuna (Yeșil x Giza $45^{\jmath}$ ) oranla daha stabil bulunmuştur.

\section{Lif verimi $\left(\mathrm{kgda}^{-1}\right)$}

Genotiplerin 2006 yılina ait lif verimi ortalamas $61.18 \mathrm{kgda}^{-1}, 2010$ yılina ait lif verimi ortalaması ise $78.68 \mathrm{kgda}^{-1}$ olarak gerçekleşmiştir (Çizelge 3). F9 generasyonunda resiproklar daha yüksek lif verimine sahip olurken, $F_{6}$ generasyonu ile $F_{9}$ generasyonu arasındaki bu farkın önemli olduğu, diğer bir anlatımla özellik yönünden genetik ilerlemenin devam ettiği saptanmıștır. Çalışmada en yüksek lif verimi; 2006 yılında Giza $45\left(80.34 \mathrm{kgda}^{-1}\right), 2010$ yılında ise Yeşil $\mathrm{X}$ Giza $45^{\widehat{\lambda}}\left(\mathrm{F}_{9}\right)$ kombinasyonundan elde edilirken, yeşil lifli ebeveyn her iki yılda da en düşük lif verimine sahip olmuştur. Açıklık ve standart sapma değerlerine göre ise ebeveynlerin resiprokal melezlerden, $\mathrm{F}_{9}$ generasyonun $\mathrm{F}_{6}$ generasyonundan, Giza $45_{+}$x Yeșil $^{\mathrm{P}^{3}}$ kombinasyonunun ise Yeşil ${ }^{\circ} \mathrm{x}$ Giza $45^{\text {t }}$ kombinasyonundan daha istikrarlı olduğu belirlenmiştir.

Çizelge 3. Genotiplerin $\mathrm{F}_{6}$ ve $\mathrm{F}_{9}$ generasyonlarına ait lif verimleri

\begin{tabular}{|c|c|c|c|c|c|}
\hline $\begin{array}{l}\text { Genotipler } \\
\left(\begin{array}{lll}0 & \left.0^{7}\right)\end{array}\right.\end{array}$ & $\begin{array}{c}\mathrm{F}_{6} \\
(2006)\end{array}$ & $\begin{array}{c}\mathrm{F}_{9} \\
(2010)\end{array}$ & $\begin{array}{c}\text { Ortalama } \\
\left(\mathrm{kgda}^{-1}\right)\end{array}$ & $\begin{array}{c}\text { Açılklı } \\
\text { (F maximum-minimum) }\end{array}$ & Standart sapma $(\delta)$ \\
\hline Giza 45 x Yeşil & 58.10 & $90.10 *$ & $74.10 \mathrm{ab}$ & 32.00 & 16.00 \\
\hline Yeşil x Giza 45 & 56.54 & $98.37 *$ & 77.46 a & 41.83 & 20.92 \\
\hline Giza 45 (ebeveyn) & $80.34 *$ & 68.93 & $74.64 \mathrm{ab}$ & 11.41 & 5.71 \\
\hline Yeşil lif (ebeveyn) & 51.33 & 59.06 & $55.20 \mathrm{~b}$ & 7.73 & 3.87 \\
\hline Ortalama & $61.18 \mathrm{~b}$ & $78.68 \mathrm{a}$ & 69.93 & & \\
\hline CV (\%) & 33.59 & 33.85 & 17.54 & & \\
\hline Açıklık ( $\left.F_{\text {maximum-minimum }}\right)$ & 29.01 & 39.31 & & & \\
\hline Standart Sapma $(\delta)$ & 20.55 & 26.63 & & & \\
\hline Lsd kombinasyonlar ort. & & & 19.60 & & \\
\hline Lsd generasyonlar ort. & & & $15.18 *$ & & \\
\hline
\end{tabular}

\section{Lif inceliği (micronaire)}

Lif inceliği uzunluktan sonra en çok aranan ve iplik kalitesini karde iplikçiliğinde $\% 20$, penye iplikçiliğinde $\% 30$, rotor iplikçiliğinde ise $\% 35$ oranında etkileyen bir özelliktir. Çalışmada, genotiplerin 2006 yılı ortalaması 4.18 micronare, 2010 yll ortalaması ise 3.39 micronaire olarak gerçekleşmiştir (Çizelge 4).

Genotiplerin $F_{9}$ generasyonuna ait değerleri, $F_{6}$ generasyonundan daha küçük bulunurken, resiprokların iki generasyonda da birbirine üstünlük sağlayamadığ 1 belirlenmiştir. Çalışmada en kalın lifler; 2006 yılında Giza 45 × Yeşil ${ }^{\widehat{t}}$ kombinasyonu ile 2010 yilında Giza 45 çeşidinden elde edilirken, en ince lifler 2006 yılında Yeșilo x Giza $45^{\wedge}$ kombinasyonu ile yeșil lifli ebeveynden, 2010 yllında ise yine yeşil lifli ebeveynden elde edilmiştir. Başbağ ve Temiz (2004), yeşil lifli genotiplerin 2.87 micronaire, Efe ve ark. (2010) ise 3.3 micronaire lif inceliğine sahip olduğunu bildirirken, bu çalışmada yer alan yeşil lifli ebeveyn 2006 yllında 4.0 micronaire, 20110 yllindada 3.12 micronaire lif inceliğine sahip olmuştur. Özellik yönünden, genotiplerin 2010 yllına ait ortalamaları, aynı çevre koşullarında çalışan Efe ve ark. (2010) ile uyum gösterirken, $F_{9}$ generayonu $F_{6}$ generayonundan, Yeşil ${ }_{+} X$ Giza $45^{\text {th }}$ kombinasyonu ise resiprokundan (Giza $45^{\circ} \mathrm{x}$ Yeşil $^{3}$ ) daha üstün bulunmuş ve aynı zamanda ebeveynleri kadar stabil olduğu, açıklık ve standart sapma değerlerinden anlaşılmıştır. 


\section{Lif uzunluğu (mm)}

Kalitsal olmakla birlikte, bir dereceye kadar çevre koșullarının etkisinde kalan bu özellik, lif ve iplik kalitesini karde ve penye iplikçiliğinde $\% 35$ oranında etkilemektedir. Bu çalışmada, genotiplerin lif uzunluk ortalaması 2006 yılında $28.69 \mathrm{~mm}, 2010$ yllına ise 28.68 mm olarak gerçekleşmiș ve özellik yönünden resiprokal melezler $\quad \mathrm{F}_{9} \quad$ generasyonunda birbirine yakın bulunmuştur. $F_{9}$ generasyonunda, Giza $45 \circ$ x Yeşil ${ }^{3}$ kombinasyonu $27.94 \mathrm{~mm}$, resiproku Yeşil x Giza $45^{3}$ melez kombinasyonu ise $27.30 \mathrm{~mm}$ lif uzunluğuna sahip olmuştur. En uzun lifler, 2006 (34.10 mm) ve 2010 (35.41 mm) yıllarında Giza 45 çeşidinden, en kısa lifler ise $2006(26.44 \mathrm{~mm})$ ve $2010(24.60 \mathrm{~mm})$ yıllarında yeşil lifli ebeveynden elde edilmiștir. Yeșil lifli ebeveyne ilgili bulgular Başbağ ve Temiz (2004)'in yanı sıra Efe ve ark. (2010) ile benzerlik gösterirken, özellik yönünden $\mathrm{F}_{6}$ ile $\mathrm{F}_{9}$ generasyonları arasında fark olmadığı ve resiprokların ebeveynlere yaklaştığı açıklık ve standart sapma değerlerinden tespit edilmiştir (Çizelge 5).

Çizelge 4. Genotiplerin $\mathrm{F}_{6}$ ve $\mathrm{F}_{9}$ generasyonlarına ait lif incelikleri

\begin{tabular}{|c|c|c|c|c|c|c|}
\hline $\begin{array}{l}\text { Genotipler } \\
\left(9 \times \delta^{\lambda}\right)\end{array}$ & $\begin{array}{c}F_{6} \\
(2006)\end{array}$ & & $\begin{array}{c}\mathrm{F}_{9} \\
(2010)\end{array}$ & $\begin{array}{c}\text { Ortalama } \\
\text { (micronaire) }\end{array}$ & $\begin{array}{c}\text { Açıklık } \\
\left(\mathrm{F}_{\text {maximum-minimum }}\right)\end{array}$ & $\begin{array}{c}\text { Standart sapma } \\
(\delta)\end{array}$ \\
\hline Giza 45 x Yeşil & 4.60 & $*$ & 3.40 & $4.00 \mathrm{a}$ & 1.20 & 0.60 \\
\hline Yeşil x Giza 45 & 4.00 & $*$ & 3.37 & $3.69 \mathrm{bc}$ & 0.63 & 0.32 \\
\hline Giza 45 (ebeveyn) & 4.10 & $*$ & 3.65 & $3.88 \mathrm{ab}$ & 0.45 & 0.23 \\
\hline Yeşil lif (ebeveyn) & 4.00 & $*$ & 3.12 & $3.56 \mathrm{c}$ & 0.88 & 0.44 \\
\hline Ortalama & 4.18 & $\mathrm{a}$ & $3.39 \mathrm{~b}$ & 3.79 & & \\
\hline $\mathrm{CV}(\%)$ & 11.30 & & 8.67 & 7.33 & & \\
\hline Açıklık (F maximum-minimum $)$ & 0.60 & & 0.52 & & & \\
\hline Standart Sapma $(\delta)$ & 0.47 & & 0.29 & & & \\
\hline Lsd kombinasyonlar ort. & & & & $0.27 * *$ & & \\
\hline Lsd generasyonlar ort. & & & & $0.21 * *$ & & \\
\hline
\end{tabular}

Çizelge 5. Genotiplerin $\mathrm{F}_{6}$ ve $\mathrm{F}_{9}$ generasyonlarına ait lif uzunlukları

\begin{tabular}{|c|c|c|c|c|c|c|}
\hline $\begin{array}{l}\text { Genotipler } \\
\left(0 \times 0^{\top}\right)\end{array}$ & $\begin{array}{c}\mathrm{F}_{6} \\
(2006)\end{array}$ & $\begin{array}{c}\mathrm{F}_{9} \\
(2010)\end{array}$ & & $\begin{array}{c}\text { Ortalama } \\
(\mathrm{mm})\end{array}$ & $\begin{array}{c}\text { Açıklık } \\
\left(\mathrm{F}_{\text {maximum-minimum }}\right)\end{array}$ & Standart sapma $(\delta)$ \\
\hline Giza 45 x Yeşil & 26.60 & 27.94 & * & $27.27 \mathrm{c}$ & 1.34 & 0.67 \\
\hline Yeşil x Giza 45 & $28.90 *$ & 27.30 & & $28.10 \mathrm{bc}$ & 1.60 & 0.80 \\
\hline Giza 45 (ebeveyn) & 34.10 & 35.41 & & $34.76 \mathrm{a}$ & 1.31 & 0.65 \\
\hline Yeşil lif (ebeveyn) & 23.80 & 25.40 & * & $24.60 \mathrm{~d}$ & 1.60 & 0.80 \\
\hline Ortalama & 28.69 & 28.68 & & 28.69 & & \\
\hline CV (\%) & 21.95 & 24.76 & & 22.96 & & \\
\hline Açılklık ( $\left.F_{\text {maximum-minimum }}\right)$ & 10.30 & 10.01 & & & & \\
\hline Standart Sapma $(\delta)$ & 6.30 & 7.10 & & & & \\
\hline Lsd kombinasyonlar ort. & & & & $1.27 * *$ & & \\
\hline Lsd generasyonlar ort. & & & & 0.98 & & \\
\hline
\end{tabular}

${ }^{*}: P<0.05,{ }^{* *}: P<0.01$

\section{Lif mukavemeti (gtex $\left.{ }^{-1}\right)$}

Karde iplikçiliğini $\% 35$, penye iplikçiliğini $\% 30$, open-end iplikçiliğini ise \%35 oranında etkileyen lif mukavemeti, kalıtsal bir özelliktir. Bu çalışmanın 2006 yllinda genotiplerin lif mukavemeti ortalamaları 29.44 gtex $^{-1}, \quad 2010$ y1linda ise 31.97 gtex $^{-1}$ olarak gerçekleşmiştir (Çizelge 6). Resiprokların $\mathrm{F}_{9}$ generasyonundaki lif mukavemetleri, $\mathrm{F}_{6}$ generasyonundan daha yüksek gerçekleşirken, Yeşil ${ }_{\odot} \mathrm{X}$ Giza $45^{-1}$ melezinin lif mukavemeti 24.90 gtex $^{-1}$ ten $\left(\mathrm{F}_{6}\right), 32.70$ gtex $^{-1} \mathrm{e}\left(\mathrm{F}_{9}\right)$, Giza 45 o x Yeșil ${ }^{3}$ melezinin lif mukavemeti ise 26.20 gtex $^{-1}$, ten $\left(\mathrm{F}_{6}\right), 30.97 \mathrm{gtex}^{-1}$ 'e $\left(\mathrm{F}_{9}\right)$ yükselmiştir. Ebeveynlerden Giza 45 çeşidi en yüksek, yeşil lifli genotipin ise en düşük lif mukavemetine sahip olduğu çalışmamıza ait bulgular, Başbağ ve Temiz (2004) ile benzerlik göstermiştir.
Özellik yönünden, $\mathrm{F}_{9}$ ve $\mathrm{F}_{6}$ generasyonları benzerlik gösterirken, Giza 45 çeșidine ait stabilitenin en yüksek, resiproklara ait stabilitenin ise en zayıf olduğu açıklık ve standart sapma değerlerinden anlaşılmıştır.

\section{Lif uzunluk uyumu (Üniformite) (\%)}

Genotiplerin 2006 yilına ait lif uzunluk uyumu ortalamas1 \% 83.89, 2010 yilına ait uzunluk uyumu ortalaması ise \% 84.10 olarak gerçekleşirken, resiprokların $\mathrm{F}_{6}$ ve $\mathrm{F}_{9}$ generasyonlarına ait lif uzunluk ortalaması $\% 83.55$ ve $\% 83.40$ olarak belirlenmiştir. Giza 45 çeşidinin en yüksek lif uzunluk uyumu ve stabiliteye sahip olduğu açıklık ve standart sapma değerlerinden anlaşılırken, bunu yeșil lifli ebeveyn ile

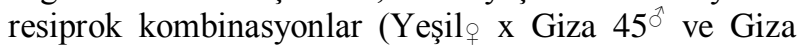
45 × Yeşi ${ }^{3}$ ) izlemiş, generasyon ortalamaları ise farksız bulunmuştur (Çizelge 7). 
Çizelge 6. Genotiplerin $\mathrm{F}_{6}$ ve $\mathrm{F}_{9}$ generasyonlarına ait lif mukavemetleri

\begin{tabular}{|c|c|c|c|c|c|}
\hline $\begin{array}{l}\text { Genotipler } \\
\left(+9 \times 0^{\pi}\right)\end{array}$ & $\begin{array}{c}\mathrm{F}_{6} \\
(2006)\end{array}$ & $\begin{array}{c}F_{9} \\
(2010)\end{array}$ & $\begin{array}{l}\text { Ortalama } \\
\left(\text { gtex }^{-1}\right)\end{array}$ & $\begin{array}{c}\text { Açıklık } \\
(\mathrm{F} \text { maximum-minimum })\end{array}$ & $\begin{array}{l}\text { Standart sapma } \\
\qquad(\delta)\end{array}$ \\
\hline Giza 45 x Yeşil & 26.20 & 30.97 & $28.59 \mathrm{bc}$ & 4.77 & 2.39 \\
\hline Yeşil x Giza 45 & 24.90 & $32.70=$ & $28.80 \mathrm{bc}$ & 7.80 & 3.90 \\
\hline Giza 45 (ebeveyn) & 40.20 & 39.60 & 39.90 a & 0.60 & 0.30 \\
\hline Yeșil lif (ebeveyn) & $26.44 *$ & 24.60 & $25.52 \mathrm{c}$ & 1.84 & 0.92 \\
\hline Ortalama & 29.44 & 31.97 & 30.71 & & \\
\hline $\mathrm{CV}(\%)$ & 41.48 & 26.79 & 32.47 & & \\
\hline Açıklık ( $\left.F_{\text {maximum-minimum }}\right)$ & 15.30 & 15.00 & & & \\
\hline Standart Sapma $(\delta)$ & 12.21 & 8.56 & & & \\
\hline Lsd kombinasyonlar ort. & & & $3.70 * *$ & & \\
\hline Lsd generasyonlar ort. & & & 2.86 & & \\
\hline
\end{tabular}

Çizelge 7. Genotiplerin $\mathrm{F}_{6}$ ve $\mathrm{F}_{9}$ generasyonlarına ait lif uzunluk uyumu

\begin{tabular}{|c|c|c|c|c|c|}
\hline 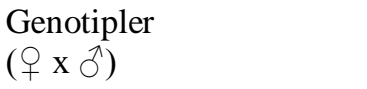 & $\begin{array}{c}\mathrm{F}_{6} \\
(2006)\end{array}$ & $\begin{array}{c}\mathrm{F}_{9} \\
(2010)\end{array}$ & $\begin{array}{l}\text { Ortalama } \\
(\%)\end{array}$ & $\begin{array}{c}\text { Açıklık } \\
(\mathrm{F} \text { maximum-minimum })\end{array}$ & $\begin{array}{c}\text { Standart sapma } \\
(\delta)\end{array}$ \\
\hline Giza 45 x Yeşil & 82.30 & $84.80 *$ & $83.55 \mathrm{~b}$ & 2.50 & 1.25 \\
\hline Yeşil x Giza 45 & $84.50 *$ & 82.30 & $83.40 \mathrm{~b}$ & 2.20 & 1.10 \\
\hline Giza 45 (ebeveyn) & 86.20 & 85.70 & $85.95 \mathrm{a}$ & 0.50 & 0.25 \\
\hline Yeşil lif (ebeveyn) & 82.54 & 83.60 & $83.07 \mathrm{~b}$ & 1.06 & 0.53 \\
\hline Ortalama & 83.89 & 84.10 & 84.00 & & \\
\hline CV $(\%)$ & 3.51 & 3.00 & 2.55 & & \\
\hline Açıklık (F maximum-minimum) & 3.90 & 3.40 & & & \\
\hline Standart Sapma $(\delta)$ & 2.95 & 2.52 & & & \\
\hline Lsd kombinasyonlar ort. $_{\text {. }}$ & & & $1.65 * *$ & & \\
\hline Lsd generasyonlar ort. & & & 1.28 & & \\
\hline
\end{tabular}

\section{SONUÇ}

Gossypium hirsutum L. türüne ait yeşil lifli pamuk genotipinin, beyaz lifli pamuklara oranla daha düşük olan kütlü pamuk verimi, çırçır randımanı ve lif kalitesini iyileştirmek bu çalışmanın temel amacıdır. Birden fazla özelliğin iyileştirilmek istendiği çalışmada, yeşil lifli genotip ile lif kalite değerleri üstün Giza 45 (Gossypium barbadense L.) çeşidi resiproklu melezlenmiş ve resiprokal kombinasyonların $\mathrm{F}_{6}$ (2006) ve $\mathrm{F}_{9}$ kuşakları (2010) karşılaştırılmıştır. Karşılaşıırıma sonucunda; kütlü pamuk verimi, çırçır randımanı, lif verimi ve lif inceliği yönünden genetik ilerlemenin $\mathrm{F}_{9}$ generasyonunda hala devam ettiği, lif uzunluğu, lif mukavemeti ve lif uzunluk uyumu yönünden ise ilerlemenin sona geldiği belirlenirken, teksel bitki seleksiyonunun kütlü pamuk verimi ve lif inceliği yönünden devam etmesi gerektiği anlaşılmıştır.

Kütlü pamuk verimi yönünden, hem $F_{6}$ hem de $F_{9}$ generasyonunda resiproklar arasinda fark bulunamazken, 2010 yilını $\left(\mathrm{F}_{9}\right) 2006$ yilından $\left(\mathrm{F}_{6}\right)$,

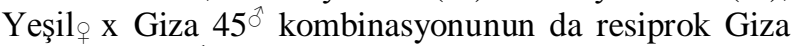
45 × Yeşil ${ }^{\widehat{x}}$ kombinasyonundan daha üstün olduğu saptanmıştır. Dahası, benzer durum lif verimi için de geçerlidir. Resiproklar, ebeveynlerden daha yüksek verim potansiyeline sahip olurken, çırçır randımanı, lif uzunluğu, lif mukavemeti ve uzunluk uyumu yönünden iki ebeveyn arasında yer almışlardır. Kütlü pamuk verimi ve lif verimi yönünden $\mathrm{F}_{6} \quad$ (2006) generasyonunun, çırçır randımanı ve lif inceliği yönünden ise $F_{9}(2010$ y1li) generasyonunun daha stabil olduğu çalışmada, $F_{6}$ ve $F_{9}$ generasyonlarının lif uzunluğu, lif mukavemeti ve lif uzunluk uyumu yönünden benzer olduğu saptanmıştır.

\section{KAYNAKLAR}

Apodaca JK 1990. Naturally Colored Cotton: A New Niche in the Texas Natural Fibers Market. Working Paper Series, Bureau of Business Research, paper number 1990-2. Austin, TX: Bureau of Business Research.

Backe E 1994. Natural colored cotton. Unpublished manuscript. Institute of Textile Technology, Charlottesville, VA.

Başbağ S, Temiz MG 2004. Determinations of some Agronomical and Technological Properties on Cotton Having Different Colors Fiber. J. Agron., 3: 301-304.

Cuming DS, Altan F, Akdemir H, Tosun M, Gürel A, Tanyolaç B 2015. QTL Analysis of Fiber Color and Fiber Quality in Naturally Green Colored Cotton (Gossypium hirsutum L.). Turkish Journal of Field Crops 2015, 20 (1): 49-58.

Fan XP, Fan BH, Xu ZQ, Yang WC 2009. Inheritance of Red Leaf and Green Fiber in Cotton and 
Their Effects on Yield and Fiber Quality. Cotton Science DOI:CNKI:SUN:MHXB.0.2009-01-007.

Fox S 1987. Naturally colored cottons: Spin-off, pp. 2931.

Efe L, Sefermustafayev A, Killı F 2010. Agronomic, Fiber and Seed Quality Traits of Naturally Colored Cottons in East Mediterranean Region of Turkey. Pak. J. Bot., 42(6): 3865-3873.

Güvercin RŞ, Şen İ, Oğlakçı M, Borzan G, Özdemir M, Göncüoğlu A, Erayman M 2007. Doğal Renkli Pamuk (Gossypium hirsutum L.) Çeșitleri ile Giza 45 (Gossypium barbadense L.) Çeşidine ait Melez Kombinasyonlarda Heterosis ve Bazı Lif Karakterlerinin İncelenmesi. Türkiye VII. Tarla Bitkileri Kongresi, 25-27 Haziran 2007 Erzurum.
Kaynak MA 1999. Lif Renkleri Farklı Pamuk (Gossypium hirsutum L.) Genotiplerinin Melez Popülâsyonlarında, Önemli Agronomik ve Teknolojik Özellikleri ile Lif Rengi Kalıtımının Saptanması. Türk Dünyasında Pamuk Tarımı Lif Teknolojisi ve Tekstil 1. Sempozyumu. 28 Eylül- 1 Ekim 1999, Kahramanmaraş-Türkiye, s; 303-314.

Richmond TR 1943. Inheritance of Brown and Green Lint in Upland Cotton. J. Am. Soc. Agron. 35:967-975.

Wu SX, Wang W, Li Z, Cui XZ 2010. The color's genetic analysis of brown cotton and the correlation between color and main characters. Hubei Agri.

Sci. 